\title{
The Nature of the Pt-H Bonding for Strongly and Weakly Bonded Hydrogen on Platinum. A XAFS Spectroscopy Study of the Pt-H Antibonding Shaperesonance and Pt-H EXAFS
}

\author{
M. K. Oudenhuijzen, J. H. Bitter, and D. C. Koningsberger* \\ Department of Inorganic Chemistry and Catalysis, Debye Institute, Utrecht University, \\ Utrecht, The Netherlands
}

Received: March 1, 2001

\begin{abstract}
A long-standing problem in the research of $\mathrm{H}_{2}$ chemisorption on supported Pt catalysts is the unclarity about the difference in nature of the $\mathrm{Pt}-\mathrm{H}$ bonding for weakly and strongly bonded hydrogen. On the basis of $\mathrm{Pt}-\mathrm{Pt}$ EXAFS and a newly developed XANES analysis of the $\mathrm{Pt} \mathrm{L}_{2}$ and $\mathrm{L}_{3}$ edges, it will be shown that both types of hydrogen are truly chemisorbed species. The EXAFS analysis shows a similar contraction of the $\mathrm{Pt}-\mathrm{Pt}$ bond irrespective of the removal of weakly or strongly bound hydrogen, indicating a similar nature for both interactions. Moreover, the analysis of the $\mathrm{L}_{2}$ and $\mathrm{L}_{3} \mathrm{X}$-ray absorption edges shows unambiguously the presence of a $\mathrm{Pt}-\mathrm{H}$ antibonding state for both the weakly and strongly bonded hydrogen. This is a clear indication for chemisorption of hydrogen for both types of hydrogen. The Pt-H EXAFS shows a smaller $\mathrm{Pt}-\mathrm{H}$ bond length in the case of strongly adsorbed, which is in correlation with the expected strength of the $\mathrm{Pt}-\mathrm{H}$ bond.
\end{abstract}

\section{Introduction}

The chemisorption of hydrogen has been a well-known standard tool in studying the metal surface area, average particle size, and dispersion of the metal (e.g., Pt) in transition-metal catalysts. ${ }^{1}$ Generally, two types of hydrogen are observed, weakly and strongly bonded to the metal. ${ }^{2-10}$ Weakly (or reversibly) adsorbed hydrogen is defined as hydrogen, which can easily be desorbed, for example, by evacuating for $10 \mathrm{~min}$ at low temperatures. ${ }^{11}$ Strongly (or irreversibly) adsorbed hydrogen is defined as hydrogen that remains on the metal surface after evacuation at room temperature. However, the term irreversible as used in the literature is confusing. Namely, this so-called irreversible adsorbed hydrogen can be removed by evacuation at higher temperatures $\left(>150{ }^{\circ} \mathrm{C}\right)$ or prolonged evacuation. ${ }^{12}$ Therefore, only the terms weakly and strongly adsorbed hydrogen will be further used in this work.

Three types of adsorption can be considered: (i) molecularly chemisorbed, (ii) atomically chemisorbed, and (iii) molecularly physisorbed. In the case of hydrogen chemisorbed on platinum, a real bond between $\mathrm{Pt}$ and atomic $\mathrm{H}$ is formed; i.e., two electrons are located in a bonding orbital between $\mathrm{Pt}$ and $\mathrm{H}$ or $\mathrm{H}_{2}$. In the case of hydrogen molecularly physisorbed, the interaction between $\mathrm{Pt}$ and molecular $\mathrm{H}_{2}$ is electrostatic; i.e., no electrons are shared in a $\mathrm{Pt}-\mathrm{H}$ bond, and no dissociation takes place.

As shown in the literature, ${ }^{13,14}$ molecularly chemisorbed hydrogen is very unlikely. When a hydrogen molecule chemisorbs on a $\mathrm{Pt}$ surface, the antibonding $\sigma^{*}$ orbital of $\mathrm{H}_{2}$ is completely filled by electrons from platinum. In addition to this, it has been shown theoretically ${ }^{13,15,16}$ and experimentally ${ }^{17}$ that dissociative chemisorption of hydrogen is nonactivated; i.e., it is not kinetically hindered. Consequently, chemisorbed hydrogen will immediately dissociate on the platinum surface, and thus, chemisorption of hydrogen on Pt can only be atomic. Therefore,

* Corresponding author. Website: http://www.anorg.chem.uu.nl/public. in this paper, only atomic (dissociative) chemisorption and molecular physisorption are considered.

It is generally accepted in the literature that the strongly adsorbed hydrogen found in a hydrogen adsorption isotherm is dissociatively chemisorbed. However, the nature of the weakly adsorbed hydrogen is still unclear: physisorbed as molecular hydrogen or chemisorbed as atomic hydrogen. Generally, this weakly adsorbed hydrogen is considered to be chemisorbed. The main argument to call this species chemisorbed rather than physisorbed is the higher energy of adsorption compared to condensation ( $\sim 20$ and $8 \mathrm{~kJ} / \mathrm{mol}$, respectively). ${ }^{1}$ However, no experimental evidence is given yet to decide upon the nature of the weakly adsorbed hydrogen. ${ }^{8}$

In this paper, the nature of the $\mathrm{Pt}-\mathrm{H}$ bond for both the weakly and the strongly adsorbed hydrogen is further investigated. A new analysis method ${ }^{18,19}$ of the $\mathrm{L}_{2}$ and $\mathrm{L}_{3}$ absorption edges of small supported platinum particles both with and without chemisorbed hydrogen is used. ${ }^{20}$ This analysis method allows the isolation of the $\mathrm{Pt}-\mathrm{H}$ antibonding state shape resonance present above the Fermi level at the $\mathrm{L}_{3}$ edge. This antibonding state originates from the chemisorption of hydrogen on the surface atoms of the Pt particles.

This paper will show that an $\mathrm{Pt}-\mathrm{H}$ antibonding state shape resonance is present for both strongly and weakly adsorbed hydrogen. Both types of hydrogen are thus atomically chemisorbed. Moreover, the difference in energy for the $\mathrm{Pt}-\mathrm{H}$ antibonding state with respect to the Fermi-level of both types of hydrogen suggests a weaker $\mathrm{Pt}-\mathrm{H}$ bond for the weakly adsorbed hydrogen. It was also possible to isolate the $\mathrm{Pt}-\mathrm{H}$ EXAFS. The differences in $\mathrm{Pt}-\mathrm{H}$ EXAFS suggest a longer $\mathrm{Pt}-\mathrm{H}$ bond for the weaker chemisorbed hydrogen, which correlates with the expected bond strengths.

\section{Experimental Section}

Catalyst Preparation. The studied $\mathrm{Pt} / \mathrm{Al}_{2} \mathrm{O}_{3}$ catalyst was prepared by incipient wetness impregnation with an aqueous 
solution of $\mathrm{Pt}\left(\mathrm{NH}_{3}\right)_{4}\left(\mathrm{NO}_{3}\right)_{2}$ on an $\mathrm{Al}_{2} \mathrm{O}_{3}$ support (pseudobohemite, Criterion). The metal loading was $2 \mathrm{wt} \%$. The sample was taken from a series of catalysts prepared to study the influence of the alkalinity on the support on the Pt particles. Therefore, the $\mathrm{Al}_{2} \mathrm{O}_{3}$ was made alkaline by impregnation of the $\mathrm{Al}_{2} \mathrm{O}_{3}$ with $\mathrm{KOH}$ solution to yield a support with $0.25 \mathrm{wt} \% \mathrm{~K}$.

The impregnated catalyst was calcined at $100{ }^{\circ} \mathrm{C}\left(1{ }^{\circ} \mathrm{C} / \mathrm{min}\right.$, $60 \mathrm{~min})$ and subsequently reduced at $350{ }^{\circ} \mathrm{C}\left(5^{\circ} \mathrm{C} / \mathrm{min}, 60 \mathrm{~min}\right)$.

Hydrogen Chemisorption. Hydrogen chemisorption measurements were performed in a conventional static volume apparatus (Micromeritics ASAP 2010). The samples were subsequently dried in $\mathrm{He}$ at $150{ }^{\circ} \mathrm{C}$ for $1 \mathrm{~h}$ (heating rate 10 ${ }^{\circ} \mathrm{C} / \mathrm{min}$ ), reduced in pure $\mathrm{H}_{2}$ at $400{ }^{\circ} \mathrm{C}$ for $1 \mathrm{~h}$ (heating rate 5 ${ }^{\circ} \mathrm{C} / \mathrm{min}$ ), and evacuated at $200{ }^{\circ} \mathrm{C}$ until an equilibrium pressure was reached (cooling rate $5{ }^{\circ} \mathrm{C} / \mathrm{min}$ ). Hydrogen adsorption isotherms were taken at $35^{\circ} \mathrm{C}$. The absolute amount of adsorbed hydrogen is determined by adding a fixed volume of $\mathrm{H}_{2}$ to a known volume containing a known amount of catalyst. From the decrease in pressure, the amount of adsorbed hydrogen can be calculated. After the first hydrogen adsorption isotherm was taken, the sample was evacuated for $10 \mathrm{~min}$ at $35^{\circ} \mathrm{C}$ (to remove weakly adsorbed hydrogen), and then a second hydrogen adsorption isotherm was taken. The second adsorption isotherm is determined by the weakly adsorbed hydrogen, whereas the difference between both isotherms gives the amount of strongly adsorbed hydrogen. The hydrogen uptake per Pt atom was calculated using the method described by Wilson and Hall. ${ }^{21}$ It was confirmed that the bare support did not show any hydrogen uptake.

XAFS Data Collection. XAFS measurements were performed at the HASYLAB synchrotron (beamline $X$ 1.1) in Hamburg, Germany, and at the European Synchrotron Radiation Facility (beamline BM 29) in Grenoble, France. The measurements were done in transmission mode using ion chambers filled with a mixture of $\mathrm{Ar}$ and $\mathrm{N}_{2}$ to have a $\mu x$ of $20 \%$ in the first and a $\mu x$ of $80 \%$ in the second ion chamber. The monochromator was detuned to $50 \%$ at maximum intensity to avoid higher harmonics present in the X-ray beam.

The catalyst sample (approximately $130 \mathrm{mg}$, resulting in a total absorption of 2.5 after the $\mathrm{Pt} \mathrm{L}_{2}$ edge) was pressed in a self-supporting wafer and mounted in a stainless steel in situ cell equipped with Be-windows. ${ }^{22}$ Both the $\mathrm{Pt} \mathrm{L}_{2}$ and $\mathrm{L}_{3}$ edge XAFS spectra were recorded at liquid nitrogen temperature in transmission mode.

The sample was in situ dried at $150{ }^{\circ} \mathrm{C}$ for $1 \mathrm{~h}$ (heating rate $10{ }^{\circ} \mathrm{C} / \mathrm{min}$ ) in $\mathrm{He}$ and subsequently reduced at $400{ }^{\circ} \mathrm{C}$ for $1 \mathrm{~h}$ (heating rate $5{ }^{\circ} \mathrm{C} / \mathrm{min}$ ) in flowing hydrogen and cooled in a hydrogen atmosphere. This sample is considered to be fully covered with hydrogen, further denoted by RED400. Next, the first EXAFS data for both the $\mathrm{L}_{2}$ and $\mathrm{L}_{3}$ edge were collected $\left(T=-196{ }^{\circ} \mathrm{C}\right)$. Subsequently, the sample was evacuated at $50,100,150$, and $200{ }^{\circ} \mathrm{C}$ (all heating rates were $5^{\circ} \mathrm{C} / \mathrm{min}$ ) for 30 min. After each evacuation, the $\mathrm{L}_{2 / 3}$ EXAFS data were collected maintaining a vacuum better then $10^{-3} \mathrm{~Pa}$ at $T=-196$ ${ }^{\circ} \mathrm{C}$. The sample after evacuation at $50{ }^{\circ} \mathrm{C}$ is considered to be covered with strongly adsorbed hydrogen only (further denoted by VAC50), while the sample after evacuation at $200{ }^{\circ} \mathrm{C}$ is hydrogen-free (further denoted by VAC200).

EXAFS Data Analysis. The absorption data was backgroundsubtracted using standard procedures. ${ }^{23,24}$ Data analysis was performed by multiple shell fitting in $R$-space $(1.6<R<3.2$ $\AA, 2.5<k<14 \AA^{-1}, k$-weighting 2 ) using the commercially available data analysis package XDAP. ${ }^{25}$ The variances in imaginary and absolute parts were used to determine the fit quality. ${ }^{24}$ Different backscatterers were identified by applying the difference-file technique ${ }^{26}$ using phase-corrected Fourier transforms. Data for the phase shifts and backscattering amplitudes were obtained form reference compounds. The references were theoretical $\mathrm{Pt}-\mathrm{Pt}$ and $\mathrm{Pt}-\mathrm{O}$ references ${ }^{27}$ generated by the FEFF7 code $^{28}$ and calibrated with experimental spectra of Pt-foil and $\mathrm{Na}_{2} \mathrm{Pt}(\mathrm{OH})_{6} \cdot{ }^{27}$ The references can be used for $k>2.5 \AA^{-1}$.

Near-Edge Analysis of the $\mathbf{P t} \mathbf{L}_{2}$ and $\mathbf{L}_{3}$ Absorption Edges. The $L_{2}$ and $L_{3}$ whiteline areas with and without hydrogen change dramatically. ${ }^{19}$ A special alignment and subtraction procedure has been developed to isolate the $\mathrm{Pt}-\mathrm{H}$ antibonding state shaperesonance and $\mathrm{Pt}-\mathrm{H}$ EXAFS. Details are given elsewhere. ${ }^{19,29}$ The difference in XAFS scattering due to the geometric changes of the Pt cluster is dominated at low energies by $\mathrm{Pt}-\mathrm{H}$ scattering. ${ }^{19}$ The $\mathrm{Pt}-\mathrm{H}$ EXAFS can be approximated with a theoretical $\mathrm{Pt}-\mathrm{H}$ EXAFS function (calculated with the FEFF7 $\operatorname{code}^{28}$ ). This allows a determination of the $\mathrm{Pt}-\mathrm{H}$ bondlength.

On the basis of the earlier developed methods, the $\mathrm{Pt}-\mathrm{H}$ shaperesonance and $\mathrm{Pt}-\mathrm{H}$ EXAFS for weakly and strongly adsorbed hydrogen can be isolated from the experimental data as follows:

Starting with three samples (the fully covered, the sample with strongly adsorbed hydrogen, and the hydrogen-free sample), two models for hydrogen adsorption can be considered. The first model is that in the fully covered sample (RED400), both weakly and strongly adsorbed hydrogen are present at different sites. The weakly adsorbed hydrogen can then be isolated by subtracting the XAFS data of the sample with the strongly adsorbed hydrogen (VAC50) from data of the fully covered sample (weakly adsorbed, RED400-VAC50). The second model is that in the fully covered sample all hydrogen is present as weakly adsorbed hydrogen, and that after desorption of part of the hydrogen the remaining hydrogen is stronger bonded. This can be due to a change in electronic properties of the Pt particles while desorbing hydrogen or due to a movement of the remaining hydrogen to strongly adsorbing sites (e.g., from ontop sites to bridged sites which were formerly inaccessible). In this case, the weakly adsorbed hydrogen can be isolated by subtracting the XAFS data of the hydrogen-free sample from the fully covered sample (weakly adsorbed, RED400-VAC200). For both models, the strongly adsorbed hydrogen can be isolated by subtracting the XAFS data of the hydrogen-free sample from the sample covered with strongly adsorbed hydrogen (strongly adsorbed, VAC50-VAC200).

Both models were tested in this paper. To the best of our knowledge, in the literature, the validity of the two models has not yet been investigated. The shape resonances and $\mathrm{Pt}-\mathrm{H}$ EXAFS for the weakly adsorbed hydrogen (using both models) and the strongly adsorbed hydrogen were isolated and analyzed.

\section{Results}

Hydrogen Adsorption. The adsorption isotherms for the Pt/ $\mathrm{Al}_{2} \mathrm{O}_{3}$ sample are given in Figure 1. The hydrogen uptakes were determined by extrapolating the linear parts of the adsorption isotherms to $P=0 \mathrm{mmHg}$. The total amount of adsorbed hydrogen was determined by the first adsorption isotherm (solid line) and resulted in $\mathrm{H}_{\text {total }} / \mathrm{Pt}=0.70$. The amount of weakly adsorbed hydrogen is given by the second adsorption isotherm (dotted line), the amount of strongly adsorbed hydrogen by the difference (dashed-dotted line) between to the two adsorption isotherms. This resulted in $\mathrm{H}_{\text {strong }} / \mathrm{Pt}=0.36$ and $\mathrm{H}_{\text {weak }} / \mathrm{Pt}=0.34$.

EXAFS Data Analysis. In Figure 2a, the raw EXAFS data is shown after reduction (RED400, solid line), after evacuation 


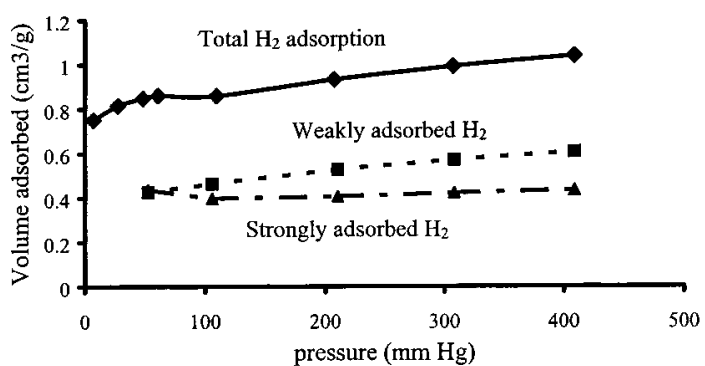

Figure 1. First hydrogen adsorption isotherm (total hydrogen adsorption, solid line with diamonds) and second hydrogen adsorption isotherm (weakly adsorbed hydrogen, dotted line with squares) of $\mathrm{Pt} / \mathrm{Al}_{2} \mathrm{O}_{3}$. The difference between these two adsorption isotherms is the strongly adsorbed hydrogen (dashed-dotted line with triangles).

at $50{ }^{\circ} \mathrm{C}$ (VAC50, dotted line), and after evacuation at $200{ }^{\circ} \mathrm{C}$ (VAC200, dashed-dotted line). It is clearly shown that the evacuation treatment changed the nodes of the oscillations. The distance between the nodes increases in the order RED400 < VAC50 < VAC200. This indicates a decrease in the Pt $-\mathrm{Pt}$ bond distance in the order RED400 > VAC50 > VAC200.

In Figure 2B-D, the corresponding Fourier transforms $\left(k^{2}\right.$, $\left.\Delta k=2.5-14 \AA^{-1}\right)$ and best-fits are shown. Data analysis has been performed by multiple-shell fitting in $R$-space $(1.6<R<$ $3.2 \AA)$. The $\mathrm{O}$ and Pt backscatterers were identified using the difference-file technique. It has been shown earlier that the oxygen backscatterers originate from the metal-support interface. ${ }^{30-32}$ The variances in imaginary and absolute parts were used to determine the fit quality. The best-fit results are given in Table 1 . It can be seen (Figure 3 ) that after the desorption of hydrogen at low temperature, the first metal-shell distance ( $\mathrm{Pt}-\mathrm{Pt}$ distance) decreases with 1-2\% compared to the sample in a $\mathrm{H}_{2}$ atmosphere. After evacuation at $150^{\circ} \mathrm{C}$ and $200{ }^{\circ} \mathrm{C}$, a further decrease of again $1-2 \%$ was observed. This is in agreement with the observation of the decrease in the distance between the nodes as seen in the raw EXAFS data.

The Pt-Pt first-shell coordination number decreased slightly, while the coordination number of he $\mathrm{Pt}-\mathrm{O}_{\text {support }}$ coordination increased after evacuation at $150{ }^{\circ} \mathrm{C}$. After evacuation at 200 ${ }^{\circ} \mathrm{C}$, the $\mathrm{Pt}-\mathrm{Pt}$ coordination number increased again. The $\mathrm{Pt}-$ $\mathrm{O}_{\text {support }}$ coordination number remained relatively high at this temperature.

Isolation of the $\mathbf{P t}-\mathbf{H}$ Antibonding State Shape Resonance. In Figure 4, the near-edge spectra of the $L_{2}$ and $L_{3}$ edge of the samples RED400, VAC50, and VAC200 after the alignment procedure as described in ref 19 are shown. The $\mathrm{L}_{2}$ spectra are aligned at a step height of 0.6. The $\mathrm{L}_{3}$ edges are aligned at their corresponding $\mathrm{L}_{2}$ edges by fitting the EXAFS wiggles at $100-500 \mathrm{eV}$ over the edge using the least-squares method. The region below $100 \mathrm{eV}$ cannot be used for alignment since all differences in the $\mathrm{L}_{2}$ and $\mathrm{L}_{3}$ edges are present in this energy window. The region higher than $500 \mathrm{eV}$ was not used since the noise level is too high at these energies. It can be seen that after evacuation the intensity of the $\mathrm{L}_{2}$ whiteline decreases, while the $\mathrm{L}_{3}$ whitelines sharpen and start at lower energies after evacuation. Clearly, the influence of chemisorption of hydrogen is different for $\mathrm{L}_{2}$ than for $\mathrm{L}_{3}$ edges.

By taking the difference VAC50-VAC200 (as described in the Experimental Section and in ref 19), we isolated the $\mathrm{Pt}-\mathrm{H}$ AS (Figure 5) for the strongly adsorbed hydrogen. Also, RED400 was used to subtract VAC50 (giving weakly adsorbed hydrogen according to model 1) and VAC200 (giving weakly adsorbed hydrogen in model 2), giving a $\mathrm{Pt}-\mathrm{H}$ EXAFS and a $\mathrm{Pt}-\mathrm{H}$ AS
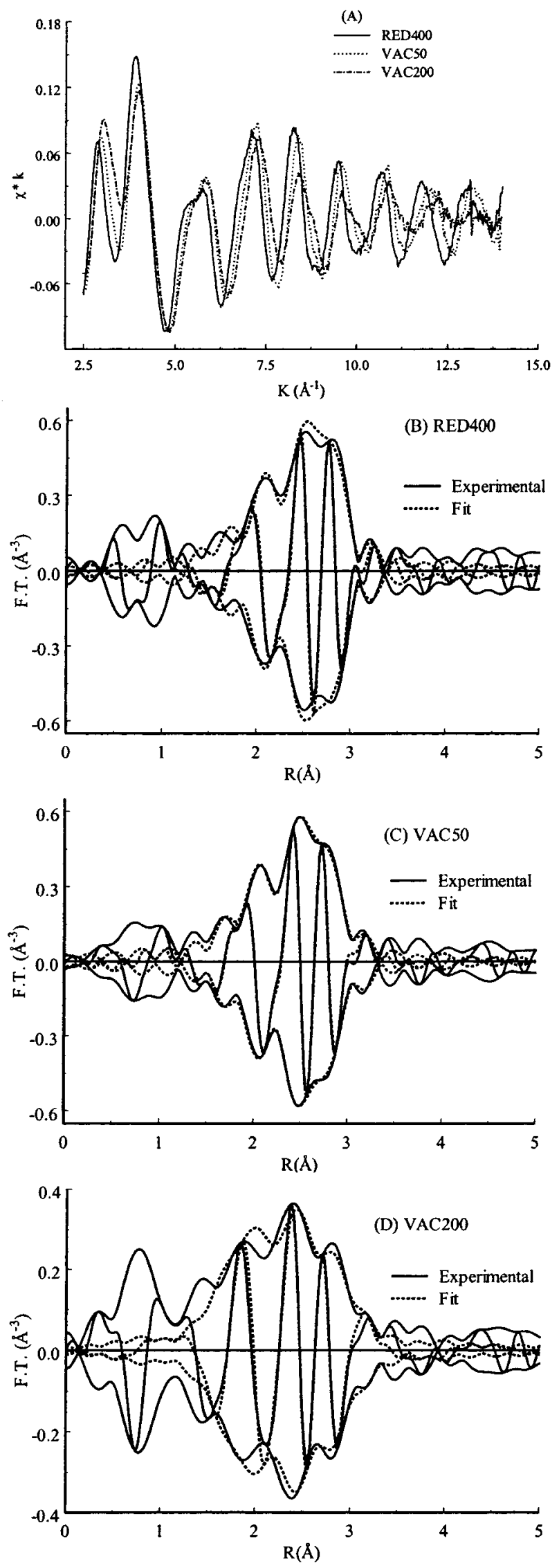

Figure 2. (A) $k^{1}$-weighted EXAFS spectra of $\mathrm{Pt} / \mathrm{Al}_{2} \mathrm{O}_{3} \mathrm{~L}_{3}$ edge after reduction (solid line), after evacuation at $50{ }^{\circ} \mathrm{C}$ (dotted line), and after evacuation at $200{ }^{\circ} \mathrm{C}$ (broken line) and the corresponding Fourier transforms (solid line) with best total fit (dotted line) ( $R$-space fit, 1.6 $\AA<R<3.2 \AA$, $k^{2}$-weighted, $2.5<k<14 \AA^{-1}$ ) (B) after reduction, (C) after evacuation at $50{ }^{\circ} \mathrm{C}$, and (D) after evacuation at $200{ }^{\circ} \mathrm{C}$. 
TABLE 1: Fit Results for All Samples ${ }^{a}$

\begin{tabular}{lccccccc}
\hline sample & scatterer & $\begin{array}{c}N \\
( \pm 10 \%)\end{array}$ & $\begin{array}{c}R(\AA) \\
( \pm 0.02 \AA)\end{array}$ & $\begin{array}{c}\Delta \sigma^{2}\left(\AA^{2}\right) \\
( \pm 5 \%)\end{array}$ & $\begin{array}{c}E_{0}(\mathrm{eV}) \\
( \pm 10 \%)\end{array}$ & $\begin{array}{c}\text { variance } \\
\text { imaginary }\end{array}$ \\
\hline reduced & $\mathrm{Pt}$ & 6.5 & 2.75 & 0.0041 & 1.2 & 0.868 & 0.308 \\
$400^{\circ} \mathrm{C}$ & $\mathrm{O}$ & 0.3 & 2.10 & 0.0020 & -8.0 & 0.414 \\
evacuation & $\mathrm{Pt}$ & 6.5 & 2.71 & 0.0056 & -0.3 & 0.135 \\
$50^{\circ} \mathrm{C}$ & $\mathrm{O}$ & 0.3 & 2.10 & 0.0040 & -7.3 & 0.700 & 0.321 \\
evacuation & $\mathrm{Pt}$ & 6.5 & 2.71 & 0.0050 & -0.2 & 0.0 \\
$100^{\circ} \mathrm{C}$ & $\mathrm{O}$ & 0.4 & 2.10 & 0.0040 & -7.0 & 0.1 \\
evacuation & $\mathrm{Pt}$ & 5.7 & 2.69 & 0.0050 & 0.1 & 0.993 \\
$150^{\circ} \mathrm{C}$ & $\mathrm{O}$ & 0.5 & 2.10 & 0.0040 & -7.0 & 2.07 \\
evacuation & $\mathrm{Pt}$ & 6.7 & 2.68 & 0.0079 & -0.6 & 0.632 \\
$200^{\circ} \mathrm{C}$ & $\mathrm{O}$ & 0.8 & 2.10 & 0.0040 & -2.6 &
\end{tabular}

${ }^{a}$ Fits were done in $R$-space, $k^{2}$ weighting, $1.6 \AA<R<3.2 \AA$, and $\Delta K=2.5-14 \AA^{-1}$. The Debye-Waller factors are relative to the theoretical references. Accuracy limits ${ }^{37}$ between brackets.

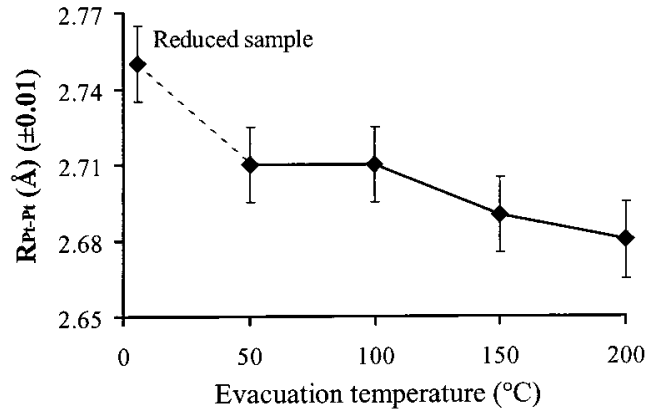

Figure 3. $\mathrm{Pt}-\mathrm{Pt}$ coordination distance as a function of the treatment of the sample.

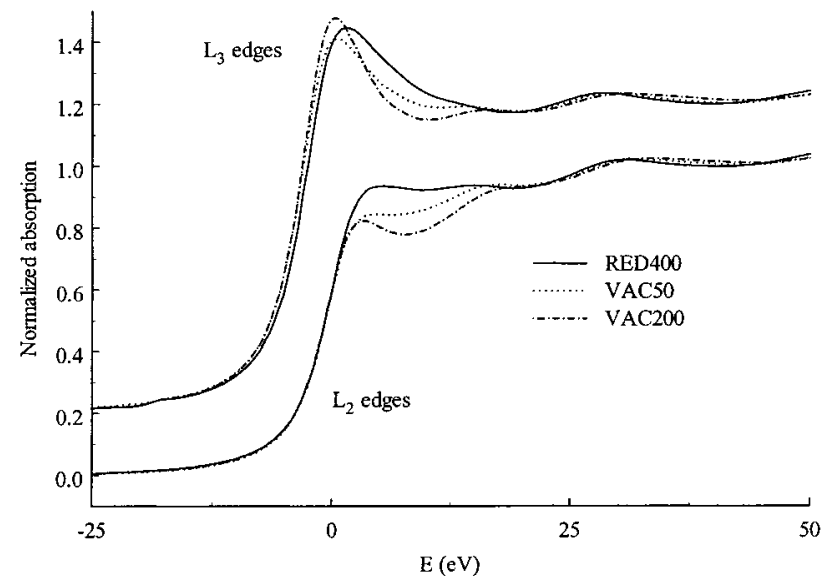

Figure 4. $\mathrm{L}_{2}$ and $\mathrm{L}_{3}$ edges after $\mathrm{H}_{2}$ chemisorption, after evacuation at $50{ }^{\circ} \mathrm{C}$, and at $200{ }^{\circ} \mathrm{C}$.

The position and shape of the shaperesonance depend on multiple parameters: ${ }^{19}$ the amplitude $A$, energy $E_{\text {res }}$, width $\Gamma$, and phase $\Phi$. $\Phi$ can be calculated as described in ref 29. $A$, $E_{\text {res, }}$ and $\Gamma$ can be obtained by fitting the line shape with the Fano expression. ${ }^{19}$ The best fit was determined by the leastsquares method. The shaperesonance was fitted in the energy range of -20 to $5 \mathrm{eV}$. The region $5-20 \mathrm{eV}$ was not taken into account, since the bumps present in this region can be attributed to differences in Atomic XAFS between the $\mathrm{L}_{2}$ and $\mathrm{L}_{3}$ edge for the bare sample and the hydrogen-covered samples. The different parameters describing both $\mathrm{Pt}-\mathrm{H}$ AS shaperesonance line shapes are compiled in Table 2 . The best fit for the strongly adsorbed hydrogen gives an energy of the antibonding state of $-0.3 \mathrm{eV}$. The energy of the AS for the weakly adsorbed hydrogen in model 2 (RED400-VAC200) was found to be -1.7 $\mathrm{eV}$. In the case of model 1, the AS of the weakly adsorbed hydrogen (RED400-VAC50) has an energy of $-2.5 \mathrm{eV}$.

Isolation of Pt-H EXAFS. In Figure 6, the difference in XAFS obtained for the strongly adsorbed hydrogen, the weakly
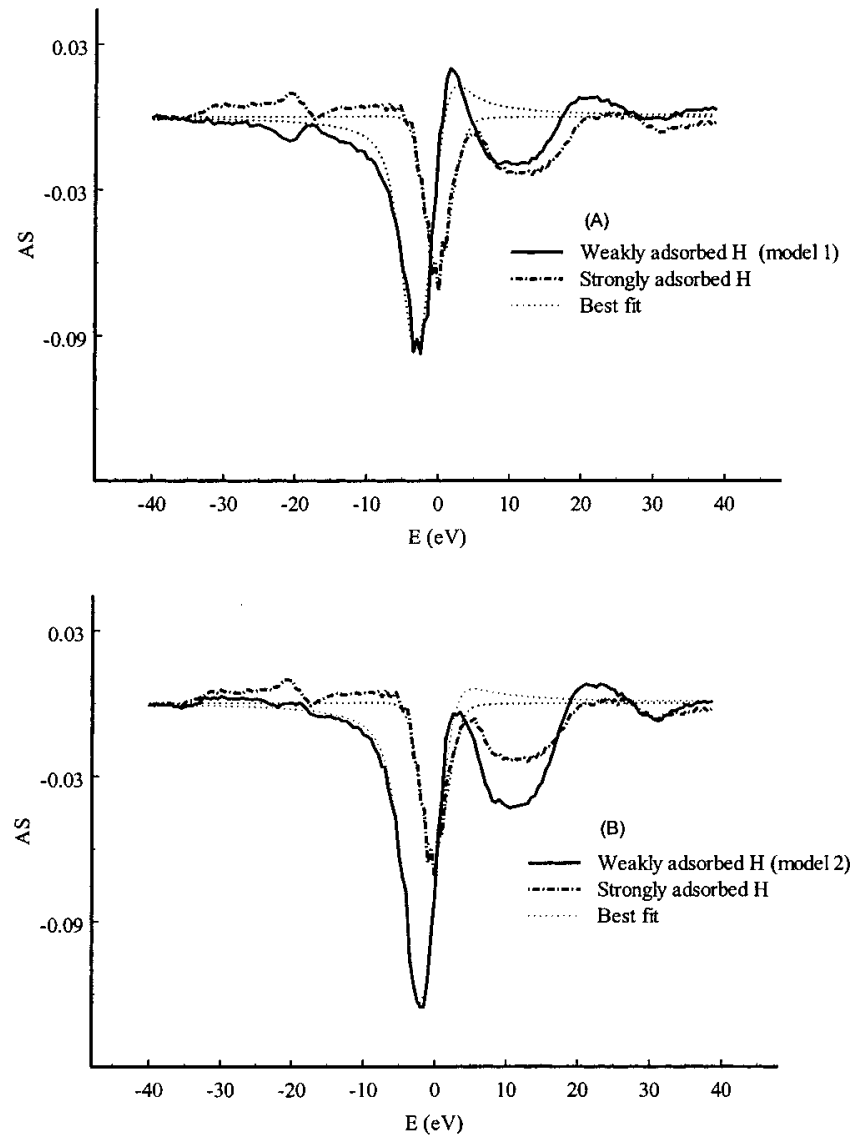

Figure 5. Shaperesonance of the $\mathrm{Pt}-\mathrm{H}$ antibonding state for the weakly (solid line) and strongly (broken-dotted line) adsorbed hydrogen in (A) model 1 (simultaneous adsorption) and (B) model 2 (rearrangement of $\mathrm{H})$ with the corresponding fits (dotted line).

TABLE 2: Fit Parameters for the Isolated Shaperesonances ${ }^{a}$

\begin{tabular}{lccc}
\hline \multicolumn{1}{c}{ isolated AS } & amplitude & $\begin{array}{c}\text { energy }(\mathrm{eV}, \\
\left.\text { relative to } \mathrm{E}_{\mathrm{F}}\right)\end{array}$ & width $(\mathrm{eV})$ \\
\hline $\begin{array}{c}\text { RED400-VAC50 (model 1 } \\
\text { for weakly adsorbed H) }\end{array}$ & 0.22 & -2.5 & 1.7 \\
$\begin{array}{c}\text { RED400-VAC200 (model 2 } \\
\quad \text { for weakly adsorbed H) }\end{array}$ & 0.16 & -1.7 & 2.5 \\
$\begin{array}{l}\text { VAC200-VAC50 } \\
\text { ( }\end{array}$ & 0.28 & -0.3 & 0.3
\end{tabular}

(strongly adsorbed)

${ }^{a}$ Parameters obtained from non-linear least-squares fit of the Fano profile to the hydrogen-induced shape-resonance in experimental spectra. Applied experimental width: Gaussian, $5 \mathrm{eV}$.

adsorbed hydrogen according to model 1 (simultaneous adsorption), and the weakly adsorbed hydrogen according to model 2 (rearrangement of hydrogen) are shown. This difference in XAFS is dominated by $\mathrm{Pt}-\mathrm{H}$ EXAFS. ${ }^{19}$ The amplitude of $\mathrm{H}$ 


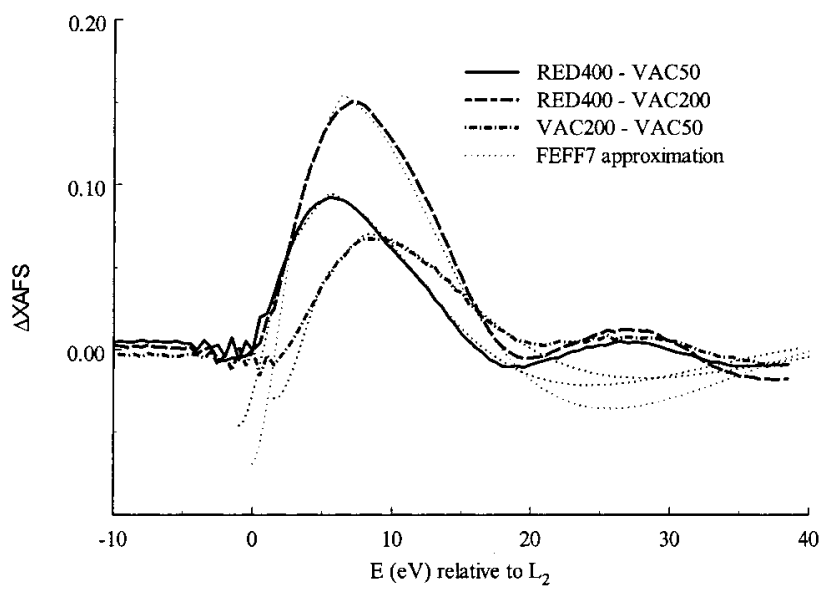

Figure 6. Difference $\left(\mathrm{L}_{2}\right.$ in a vacuum- $\mathrm{L}_{2}$ in hydrogen $)$ spectra with $\mathrm{Pt}-\mathrm{H}$ EXAFS for weakly adsorbed hydrogen in model 1 (solid line), model 2 (dashed line), and strongly adsorbed hydrogen (dashed-dotted line) and the FEFF7 ${ }^{28} \mathrm{Pt}-\mathrm{H}$ calculation (dotted line) with $\mathrm{Pt}-\mathrm{H}=$ $1.89 \AA$ (strongly adsorbed $\mathrm{H}_{2}$ ), $\mathrm{Pt}-\mathrm{H}=1.92 \AA$ (weakly adsorbed $\mathrm{H}_{2}$ in model 2), and $\mathrm{Pt}-\mathrm{H}=1.94 \AA$ (weakly adsorbed $\mathrm{H}_{2}$ in model 1 ).

TABLE 3: Input Parameters for FEFF7 Calculations

\begin{tabular}{ll}
\hline parameter & value(s) \\
\hline control & 1111 \\
print & 0000 \\
hole & 30.82 \\
criteria & 2.01 .25 \\
$N_{\operatorname{leg}}$ & 6 \\
$R_{\max }$ & 8.3 \\
exchange & 143 \\
potentials & \\
078 & $\mathrm{Pt}$ \\
11 & $\mathrm{H}$ \\
atoms & \\
0000 & \\
$1.94^{a} 001$ &
\end{tabular}

${ }^{a}$ This parameter (the $\mathrm{Pt}-\mathrm{H}$ distance) was varied.

scattering is near zero above $k=2 \AA^{-1}$, since $\mathrm{H}$ has a crosssection for scattering which decreases stongly with increasing values of $k$. A consequence is that no experimental $\mathrm{Pt}-\mathrm{H}$ reference is available to do normal EXAFS analysis on the isolated $\mathrm{Pt}-\mathrm{H}$ EXAFS. However, since the distance of the nodes in oscillations is different, it is expected that the $\mathrm{Pt}-\mathrm{H}$ distance in the two samples is different. To quantify these differences, we used FEFF7 ${ }^{28}$ to calculate the $\mathrm{Pt}-\mathrm{H}$ XAFS for different $\mathrm{Pt}-\mathrm{H}$ distances. An on-top adsorption site for hydrogen was assumed. The input parameters are given in Table 3 . The only input-parameter that was varied was the $\mathrm{Pt}-\mathrm{H}$ distance. The calculated $\mathrm{Pt}-\mathrm{H}$ EXAFS was used to fit the experimentally observed $\triangle X A F S$. To obtain a good fit, we shifted the theoretical data in energy until the onset of the theoretical $\mathrm{Pt}-\mathrm{H}$ EXAFS spectrum was aligned with the experimental data. Then the theoretical spectrum was scaled until the theoretical and experimental maxima were in agreement. The quality of the fit was then judged on the right part of the $\mathrm{Pt}-\mathrm{H}$ first wiggle, since the left part of the theoretical spectrum was fixed at perfect alignment with the experimental spectrum. The best fits are shown in Figure 6 (dotted lines). For strongly adsorbed hydrogen, it was found that the $\mathrm{Pt}-\mathrm{H}$ bond is $1.89 \AA$, whereas weakly adsorbed hydrogen was found at $1.94 \AA$ from Pt in model 1 and at $1.92 \AA$ in model 2 . The small bumps around 25-30 eV in the experimental curve which cannot be reproduced by the theoretical curve are caused by the differences in $\mathrm{Pt}-\mathrm{Pt}$ EXAFS. These differences are due to the decrease in $\mathrm{Pt}-\mathrm{Pt}$ bond length after the evacuation treatments.

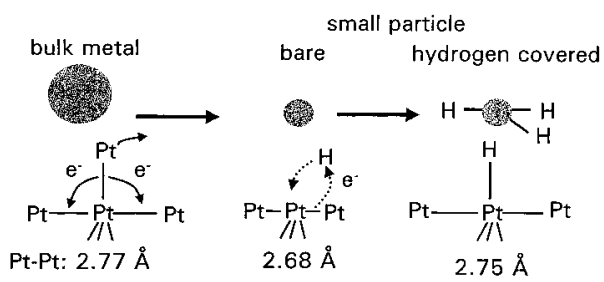

Figure 7. $\mathrm{Pt}-\mathrm{Pt}$ bond length is shortened going from bulk metal to small particles and enlarged by chemisorbing hydrogen.

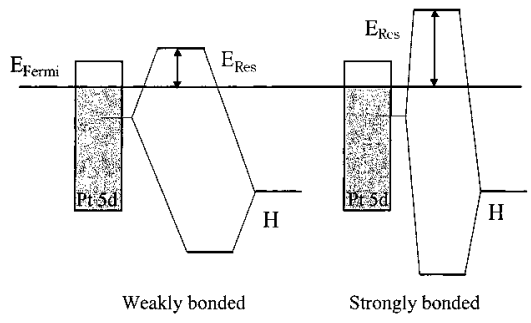

Figure 8. Molecular orbital (MO) scheme of $\mathrm{Pt}-\mathrm{H}$ interaction showing the effect of differences in orbital overlap on the strength of the $\mathrm{Pt}-\mathrm{H}$ bond-strength.

\section{Discussion}

Pt-Pt Coordination Distance. Figure 3 shows a decrease in $\mathrm{Pt}-\mathrm{Pt}$ bond length of ca. 1-2\% after desorption of weakly adsorbed hydrogen and again a decrease of $1-2 \%$ after desorption of strongly adsorbed hydrogen.

A decrease of the metal-metal coordination distance is expected going from bulk to very small metal particles, owing to a softening of the phonon spectrum caused by the dehybridization of the spd metal orbitals. ${ }^{33}$ The dehybridization results in increased electron density between the atoms in the small particle, which in turn results in a contraction in the interatomic distance. However, for small particles covered with chemisorbed hydrogen, EXAFS results show bulklike coordination distances. ${ }^{22,34}$ This is caused by the electron-withdrawing properties of hydrogen chemisorbed on $\mathrm{Pt},{ }^{35}$ leading to a decrease in electron-density between the atoms. ${ }^{33}$ This is illustrated in Figure 7. A longer $\mathrm{Pt}-\mathrm{Pt}$ bond length is observed going from the hydrogen free sample to the sample covered with strongly adsorbed hydrogen and again going from the latter species to the fully covered sample (Table 1). This is a strong indication that both types of hydrogen are chemisorbed.

Pt-H Antibonding State Shaperesonance. Regardless of the methods used (model 1 or model 2) to determine the weakly adsorbed hydrogen, a $\mathrm{Pt}-\mathrm{H}$ antibonding state shaperesonance is present for both the weakly and the strongly adsorbed hydrogen (shown in Figure 5). Moreover, the value of the energy of the antibonding state is larger for the strongly adsorbed species. The sheer presence of an antibonding state for the weakly chemisorbed hydrogen in itself is evidence that the weakly adsorbed hydrogen is indeed chemisorbed on the $\mathrm{Pt}$ cluster. Physisorption of molecular hydrogen on the Pt clusters or sorption of the hydrogen on the support would not result in a $\mathrm{Pt}-\mathrm{H}$ antibonding state.

The lower energy of the antibonding state of the weakly adsorbed hydrogen compared to that of the strongly adsorbed hydrogen $(-0.3 \mathrm{eV})$ shows that the weakly adsorbed hydrogen indeed has a weaker $\mathrm{Pt}-\mathrm{H}$ bond than the strongly adsorbed hydrogen, since a lower energy of the antibonding state is the result of a weaker $\mathrm{Pt}-\mathrm{H}$ bond (Figure 8 ).

Pt-H EXAFS. Normally, the starting point of the EXAFS region is taken at about $k=2.5 \AA^{-1}$. As discussed earlier, at this energy, a hydrogen does not contribute to the EXAFS as a 
backscatterer due to the small absorption cross section of hydrogen. However, the procedure described in this paper and by Ramaker et al. ${ }^{19}$ isolates the Pt-H EXAFS for $0<k<2.5$ $\AA^{-1}$. The isolated $\mathrm{Pt}-\mathrm{H}$ EXAFS could be analyzed using theoretical spectra generated by the FEFF7 ${ }^{28}$ code. For the calculations, a single Pt atom was considered to be bonded to a single hydrogen atom at varying distances. Multiple scattering was not taken into account.

The experimental $\mathrm{Pt}-\mathrm{H}$ EXAFS (Figure 6) showed a smaller bond length for the strongly adsorbed hydrogen. Generally, a longer bond is the result of a weaker bonding. This is another indication that the weakly adsorbed hydrogen is indeed weaker bonded on the Pt particles.

$\mathbf{P t}-\mathbf{H}$ Bond Strength. Differences in $\mathrm{Pt}-\mathrm{H}$ bond strength may result from several reasons. First, the metal clusters in a heterogeneous catalyst are small and therefore contain only small crystal surfaces and many edges and corners. The atoms on the corners and edges are coordinatively highly unsaturated and therefore will bond strongly to hydrogen atoms. So the strongest bonded hydrogen atoms may be the hydrogen atoms that are chemisorbed on the corners of the clusters. After saturation of the cluster with a monolayer of hydrogen, these corner atoms will still be relatively unsaturated and can bond to yet another hydrogen atom. This hydrogen, however, will be bonded rather weakly.

Tsuchiya et al. ${ }^{36}$ performed temperature-programmed desorption experiments of hydrogen chemisorbed on platinum. This gave rise to several desorption maxima. To explain different desorption maxima, Tsuchiya et al. ${ }^{36}$ proposed linear chemisorbed hydrogen for the weakly bonded species and bridged hydrogen for the strongly sorbed species.

Structurally different adsorption sites are also proposed by Giannantonio et al. ${ }^{8}$ They claim that adsorption energies as determined by TPD for the weakly adsorbed species are in agreement with theoretical calculations for the adsorption of hydrogen at an on-top or bridged position. The adsorption energy for the strongly adsorbed hydrogen is in agreement with calculations for adsorption of hydrogen at 3- and 4-fold symmetry surface sites.

Normally, in the literature, hydrogen chemisorption is used to determine the metal dispersion and, in relation to this, the accessible metal surface area for reactants during reactions. Now the question rises as to which hydrogen chemisorption values should be used to determine the metal dispersion and accessible surface area: the weakly, strongly, or total hydrogen chemisorption. In the literature, generally only strong adsorption is used (see, e.g., refs 6 and 10). Whatever the nature of the different adsorption sites is, both weakly and strongly adsorbed hydrogen are chemisorbed on the Pt surface and all sites are accessible to hydrogen, and thus, all these sites might be important during reactions. Therefore, this study shows that $\mathrm{H} / \mathrm{M}$ values should be based on the total amount of hydrogen adsorption. Of course, the adsorption sites for reactants other than hydrogen might be different than that for hydrogen adsorption.

\section{Conclusions}

Pt EXAFS in the presence and absence of hydrogen was used to determine the nature of hydrogen adsorbed on $\mathrm{Al}_{2} \mathrm{O}_{3}$ supported Pt particles.

Pt EXAFS analysis during evacuation at different temperatures results in a contraction of the $\mathrm{Pt}-\mathrm{Pt}$ distance with $1-2 \%$ after desorption of weakly and strongly adsorbed hydrogen. This is the result of an increased electron density between the $\mathrm{Pt}$ clusters after removal of the electron withdrawing hydrogen atoms, indicating that both types of hydrogen are chemisorbed.

A $\mathrm{Pt}-\mathrm{H}$ antibonding state for both weakly and strongly adsorbed hydrogen could be isolated using the analysis of the $\mathrm{Pt}_{2}$ and $\mathrm{L}_{3} \mathrm{X}$-ray absorption edges. The presence of a antibonding state for both types of hydrogen proofs that all hydrogen is chemisorbed on the Pt clusters. The lower energy of the antibonding state for the weakly adsorbed hydrogen compared to the strongly adsorbed hydrogen shows that this strongly adsorbed hydrogen indeed has a stronger $\mathrm{Pt}-\mathrm{H}$ bond. Since hydrogen is chemisorbed in all cases, the $\mathrm{H} / \mathrm{Pt}$ values used to determine the accessible metal surface area should be based on the total amount hydrogen adsorption.

Finally, the weakly adsorbed hydrogen shows a $\mathrm{Pt}-\mathrm{H}$ EXAFS. The $\mathrm{Pt}-\mathrm{H}$ bond length is longer for weakly adsorbed hydrogen compared to strongly adsorbed hydrogen. This again is the result of a weaker bond strength.

Acknowledgment. The European Union program for Large Scale Facilities (Contract ERBFMGECT950059) is acknowledged for financial support.

\section{References and Notes}

(1) Scholten, J. J. F.; Pijpers, A. P.; Hustings, A. M. L. Catal. Rev.Sci. Eng. 1985, 27, 151-206.

(2) McVicker, G. B.; Baker, R. T. K.; Garten, R. L.; Kugler, E. L. J. Catal. 1980, 65, 207-220.

(3) Paál, Z.; Menon, P. G. Catal. Rev.-Sci. Eng. 1983, 25, 229-324.

(4) Ahlafi, H.; Nawdali, M.; Bencheikh, A. K.; Bianchi, D. Bull. Soc. Chim. Fr. 1996, 133, 461-469.

(5) Sinfelt, J. H.; Lam, Y. L.; Cusumano, J. A.; Barnett, A. E. J. Catal. 1976, 42, 227-237.

(6) Sinfelt, J. H.; Via, G. H. J. Catal. 1979, 56, 1-11.

(7) Yang, C. H.; Goodwin, J. G., Jr. J. Catal. 1982, 78, 182-187. 115.

(8) Giannantonio, R.; Ragaini, V.; Magni, P. J. Catal. 1994, 146, $103-$

(9) Guil, J. M.; Pérez Masiá, A.; Ruiz Paniego, A.; Trejo Menayo, J. M. Thermochim. Acta 1998, 312, 115-124.

(10) Uner, D. O.; Pruski, M.; King, T. S. J. Catal. 1995, 156, 60-64. (11) Sayari, A.; Wang, H. T.; Goodwin, J. G., Jr. J. Catal. 1985, 93, $368-374$.

(12) Germer, L. H.; MacRae, A. U. J. Chem. Phys. 1962, 37, 13821386.

(13) Poulain, E.; Bertin, V.; Castillo, S.; Cruz, A. J. Mol. Catal. A 1997, 116, 385-396.

(14) Andzelm, J. Surf. Sci. 1981, 108, 561-577.

(15) Hammer, B.; Nørskov, J. K. Surf. Sci. 1995, 343, 211-220.

(16) Hammer, B.; Nørskov, J. K. Nature 1995, 376, 238-240.

(17) Barbier, J.; Lamy-Pitara, E.; Marecot, P. Bull. Soc. Chim. Belg. 1996, 105, 99-105

(18) Koningsberger, D. C.; de Graaf, J.; Mojet, B. L.; Ramaker, D. E.; Miller, J. T. Appl. Catal., A 2000, 191, 205-220.

(19) Ramaker, D. E.; Mojet, B. L.; Garriga Oostenbrink, M. T.; Miller, J. T.; Koningsberger, D. C. Phys. Chem. Chem. Phys. 1999, 1, 2293-2302.

(20) Koningsberger, D. C.; Mojet, B. L.; Miller, J. T.; Ramaker, D. E. J. Synchrotron Radat. 1999, 6, 135-141.

(21) Wilson, G. R.; Hall, W. K. J. Catal. 1970, 17, 190-206.

(22) Vaarkamp, M.; Mojet, B. L.; Modica, F. S.; Miller, J. T.; Koningsberger, D. C. J. Phys. Chem. 1995, 99, 16067.

(23) Ramaker, D. E.; Mojet, B. L.; Koningsberger, D. C.; O'Grady, W E. J. Phys.: Condens. Matter 1998, 108753-8770.

(24) Koningsberger, D. C.; Mojet, B. L.; van Dorssen, G. E.; Ramaker, D. E. Top. Catal. 2000, $10(3,4), 143-155$.

(25) Vaarkamp, M.; Linders, J. C.; Koningsberger, D. C. Phys. B 1995, 208, 159-160.

(26) Koningsberger, D. C. Stereo Chemistry and Electronic Structure Xafs Spectroscopy: Data-analysis and Applications. Physics and Chemistry of Solids, Hercules Course. Neutron and Synchrotron Radiation for Condensed Matter Studies. Applications to Solid State Physics and Chemistry; Baruchel, J., Hodeau, J. L., Lehmann, M. S., Regnard, J. R., Schlenker, C., Eds.; Springer-Verlag: New York, 1994; Vol. 2, pp $213-$ 244.

(27) van Dorssen, G. E.; Ramaker, D. E.; Koningsberger, D. C. Phys. Rev. B, submitted for publication. 
(28) Zabinsky, S. I.; Rehr, J. J.; Ankudinov, A.; Albers, R. C.; Eller, M. J. Phys. Rev. B 1995, 52 (4), 2995-3009.

(29) Koningsberger, D. C.; Oudenhuijzen, M. K.; Bitter, J. H.; Ramaker, D. E. Top. Catal. 2000, 10, 167-177.

(30) Van Zon, J. B. A. D.; Koningsberger, D. C.; Van 't Blik, H. F. J.; Prins, R.; Sayers, D. E. J. Chem. Phys. 1984, 80, 3914.

(31) Vaarkamp, M.; Modica, F. S.; Miller, J. T.; Koningsberger, D. C. J. Catal. 1993, 144, 611-626.

(32) Vaarkamp, M.; Miller, J. T.; Modica, F. S.; Koningsberger, D. C. J. Catal. 1996, 163, 294-305.
(33) Delley, B.; Ellis, D. E.; Freeman, A. J.; Baerends, E. J.; Post, D. Phys. Rev. B 1983, 27, 2132-2144.

(34) Kampers, F. W. H.; Koningsberger, D. C. Faraday Discuss. Chem. Soc. 1990, 89, 137-141.

(35) Sanchez Marcos, E.; Jansen, A. P. J.; van Santen, R. A. Chem. Phys. Lett. 1990, 167, 399-406.

(36) Tsuchiya, S.; Amenomiya, Y.; Cvetanovic, R. J. J. Catal. 1970, 19, 245-255.

(37) Li, G. G.; Bridges, F.; Booth, C. H. Phys. Rev. B 1995, 52 (9), 6332 . 